\title{
Comparison of Two Different Approaches to Solve Economic Load Dispatch Problem
}

\author{
Pavneet. K Makkar ${ }^{1}$, Amarjeet Kaur ${ }^{2}$ \\ ${ }^{1}$ M. Tech Student, Power System, BBSBEC, Punjab, India \\ ${ }^{2}$ Assistant Professor, Electrical Engineering Department, BBSBEC, Punjab, India
}

\begin{abstract}
The basic purpose of economic dispatch is to allocate the generation of dissimilar units in such a way that the total fuel cost is minimum and at the similar time over-all demand as well as losses at any prompt movement must be equal to the total generation. Many conventional approaches like Lagrange multiplier method, gradient search method and Newton's method etc. are applied in previous work. In these conventional techniques, it is difficult to get the optimal solution of the problem. So, in this paper Artificial Bee Colony optimization algorithm is used to solve the ELD problem Artificial bee colony optimization is a swarm-based algorithm inspired by the food foraging behavior of honey bees and reduce fuel cost by using MATLAB Software.
\end{abstract}

Keywords: Economic load dispatch, Artificial Bee Colony algorithm, Fuel Cost, Lambda Iteration Method, Matrix Laboratory (MATLAB).

\section{Introduction}

An electric power system is a network of electrical components used to supply, transmit and use electric power. With large interconnection of power system, the energy crisis and price hikes, it is very essential to reduce the operating cost of the generator. Today the major problem for all a power utilities is just not to satisfy the consumer demand but also to do it in the most economical way. Any power system can consist of multiple generator units and stations, each of which has its own characteristic operating parameters. The operating cost of these generating units does not correlate with the output; therefore balancing of the load among generators is the main task to the power utilities with the maximum efficiency [1].

In typical power system, several generators are applied to deliver enough over-all output to fulfill a given total consumer demand. Each of these generating units usually has a unique cost-per-hour characteristic for its output operating range [2]. When the transmission losses are considered then it is more complicated for the utilities to account.

The main aim of the power utilities has been identified as to provide smooth electrical energy to the consumers with the assurance of minimum cost of generation [3]. Hence in order to achieve economic operation of system, the total demand must be appropriately shared among the units. This will minimize the total cost of generation for the system. [4]

There are many conventional methods that used to solve the economic load dispatch problem such as Lagrange multiplier method, lambda iteration method, gradient search method and quadratic method etc, which is less efficient and cannot predict the exact load dispatch value of the units which increases the cost of production [8]. In conventional techniques [6], it is difficult to get the optimal solution of the problem, hence it is been required to compute the economic dispatch, thus advanced computing techniques for example the natural solving algorithms are becoming popular in solving complicated problems in economic load dispatch [7].

\section{Related Work}

Subramanian et.al, 2013, has presented the method to solve the economic load dispatch using the modified firefly algorithm for IEEE 3, 6, 13 and 15 generator test case systems. Later the results were compared with the GA, DE, PSO, ABC, BBO and BFO techniques. From the simulation it was found that the MFA gave better results of total cost minimization as compared with the other mentioned algorithms. [12]

M.basu, 2013, presented artificial bee colony optimization for multi-area economic dispatch. In which artificial bee colony optimization is used for solving Multi-Area Economic Dispatch (MAED) problem with tie line constraints considering multiple fuels, prohibited operating zones, transmission losses, and valve-point loading. Considering the quality of the solution obtained, the proposed algorithm appears to be a quite promising alternative approach for solving the MAED problems in practical power system. [13]

Hardiansyah, 2013, has presented Artificial Bee Colony Algorithm for Economic Load Dispatch Problem. In this paper, the fuel cost of generators can be represented as a quadratic function of real power generation as well as satisfied constraints for minimizing of fuel cost. The obtained results are compared with the conventional technique, genetic algorithm as well as demonstrate that the $\mathrm{ABC}$ algorithm approach is more feasible and efficient for finding minimum cost.

Provas Kumar Roy et. al. 2015, proposed Krill herd algorithm applied to short-term hydrothermal scheduling problem. In this paper, krill herd algorithm (KHA) technique was employed to solve the short-term hydrothermal scheduling (HTS) problem. In this article, the potentialities of $\mathrm{DE}$ were used in KHA technique to improve the convergence speed and robustness. The practical short-term HTS problem was solved here using KHA technique in which the crossover and mutation operation of differential evolution algorithm (DEA) was employed to efficiently control the local and global search, so that premature 


\section{International Journal of Science and Research (IJSR) \\ ISSN (Online): 2319-7064}

Index Copernicus Value (2013): 6.14 | Impact Factor (2015): 6.391

convergence may be avoided and global solutions can be achieved. The quality and usefulness of the proposed algorithm was demonstrated through its application to two standard test systems.

S.Santhosh Kumar et al. 2013 presented A Detailed Study about Foraging Behavior of Artificial Bee Colony (ABC) and its Extensions. The living nature and life style of animals, birds and other living organisms can be inherited and applied to solve many real world problems. $\mathrm{ABC}$ was recently developed swam intelligence algorithm developed by Dervis Karaboga in the year 2005. In ABC, foraging is one of the behavior of honey bees to search, collect food from its food resources. Many research works had undergone about foraging behavior and it was applied to solve variety of optimization problems. This paper discusses the detailed study of different types of extensions of foraging behavior of honey bees.

R. Murugan et al., 2012, presented modified artificial bee algorithm for solving economic dispatch problem. The Artificial Bee Colony (ABC) algorithm which was inspired by the foraging behavior of honey bee swarm gives a solution procedure for solving economic dispatch problem. It provides solution more effective than Genetic Algorithm (GA), Particle Swarm Optimization (PSO) and Ant Colony Optimization (ACO). However, it was concluded that ABC was good at exploration but poor at exploitation; its convergence speed was also an issue in some cases. To overcome this deficiency, this paper proposes a Modified $\mathrm{ABC}$ algorithm (MABC). The performance of the proposed algorithm (MABC) was applied to and tested on IEEE- 6 unit and IEEE- 13 unit systems. The results of the proposed algorithm are compared with that obtained by the basic $\mathrm{ABC}$ algorithm, lambda - iteration method to prove the validity and effectiveness of the proposed algorithm.

S. Hemamalani and Sishaj $\mathbf{P}$ Simon, 2010, presented emission/economic load dispatch using Artificial Bee Colony. In this paper, a multi-objective artificial bee colony (MOABC) algorithm to solve economic/emission dispatch problem. Non-dominated sorting was employed to obtain a Pareto optimal set. Moreover fuzzy decision theory is employed to extract the best compromise solution. A numerical solution for IEEE 30-bus test system was presented to demonstrate the capability of proposed approach to generate well distributed Pareto-optimal solutions of EED problems in one single run. In addition EED problem was also solved using a weighted sum method using ABC. Results obtained from a proposed approach are compared with other techniques available in literature. Results obtained show that the proposed MOABC has a great potential in handling multi-objective optimization problem.

\section{Problem Formulation}

\subsection{Without Losses}

The simplest economic dispatch is the case where losses are neglected. Suppose there is a station with $\mathrm{N}_{\mathrm{g}}$ generators committed and the active power load demand $P_{d}$ is given, the real power generation is $\mathrm{P}_{\mathrm{gi}}$, which is to be allocated in order to minimize the cost . In this case the total generation must be equal to the total demand to be fulfilled.

$$
\begin{gathered}
F_{T}=F_{1}+F_{2}+F_{3} \ldots \ldots \ldots \ldots F_{N}=\sum_{i=1}^{N_{g}} F_{i}\left(P_{g i}\right) \\
P_{\text {Load }}-\sum_{i=1}^{N_{g}} P_{g i}=\Phi=0
\end{gathered}
$$

The optimization problem can therefore be stated as :-

$$
F=\sum_{i=1}^{N_{g}} F_{i}\left(P_{g i}\right)
$$

The above equation is to be minimized.

1) Energy balance equation

$$
\sum_{i=1}^{N_{g}} P_{g i}=P_{d}
$$

2) Inequality Constraint

$$
P_{g i}^{\text {min }} \leq P_{g i} \leq P_{g i}^{\text {max }}
$$

$\mathrm{P}_{\mathrm{gi}}=$ Real power generation

$\mathrm{P}_{\mathrm{d}}=$ Real power demand

$\mathrm{N}_{\mathrm{g}}=$ number of generation plant

$\mathrm{F}\left(\mathrm{P}_{\mathrm{gi}}\right)=$ operating fuel cost

$$
F\left(P_{g i}\right)=a_{i} P_{g i}+b_{i} P_{g i}+c_{i} R s / h
$$

\subsection{With Losses}

Since the power stations are usually spread out geographically, the transmission network losses must be taken into account to achieve true economic dispatch. Network loss is a function of unit generation. To calculate network losses, two methods are in general use. One is the penalty factors method and the other is the $B$ coefficients method. Suppose there is a station with $\mathrm{Ng}$ generators committed and the active power load demand $\mathrm{P}_{\mathrm{d}}$ is given , the real power generation is Pgi, which is to be allocated in order to minimize the cost .

$$
F_{T}=F_{1}+F_{2}+F_{3} \ldots \ldots \ldots \ldots . . . F_{N}=\sum_{i=1}^{N g} F_{i}\left(P_{g i}\right)
$$

1) Energy balance equation

$$
\sum_{i=1}^{N_{g}} P_{g i}=P_{d}+P_{L}
$$

2) Inequality equation

$$
\begin{aligned}
& \mathrm{P}_{\mathrm{gi}}=\text { Real power generation } \\
& \mathrm{P}_{\mathrm{d}}=\text { Real power demand } \\
& \mathrm{N}_{\mathrm{g}}=\text { Number of generation plant } \\
& \mathrm{F}\left(\mathrm{P}_{\mathrm{gi}}\right)=\text { Operating fuel cost } \\
& \quad F\left(P_{g i}\right)=a_{i} P_{g i}{ }^{2}+b_{i} P_{g i}+c_{i} R s / h
\end{aligned}
$$

Expressing the transmission losses as the function of generator power is through B - Coefficient as 


\section{International Journal of Science and Research (IJSR)}

ISSN (Online): 2319-7064

Index Copernicus Value (2013): 6.14 | Impact Factor (2015): 6.391

$$
P_{L}=\sum_{i=1}^{N_{g}} \sum_{i=1}^{N_{g}} P_{g i} B_{i g} P_{g j} \quad M W
$$

The above equation is known as George's equation.

$\mathrm{P}_{\mathrm{gi}}$ and $\mathrm{P}_{\mathrm{gj}}$ are real power generation at $\mathrm{i}_{\mathrm{th}}$ and $\mathrm{j}_{\mathrm{th}}$ bus. $\mathrm{B}_{\mathrm{ij}}$ is the loss coefficient.

\section{Proposed Methodology}

\subsection{Lambda Iteration Method}

One of the most popular traditional technique to solve ELD problem is lambda iteration method. Although in lambda iteration technique computational procedure is complex but it converges very fast for this type of optimization problem. The detailed algorithm of lambda iteration method for Economic Load Dispatch problem is given below:

Step 1 : Read given data, for example cost coefficients , Bcoefficients, power limits and power demand.

Step 2 :Assume the starting value of $\lambda$ and $\Delta \lambda$.

Step 3 :Calculate generated power $\mathrm{P}_{\text {gi }}$ from each unit.

Step 4 :Check generation limit for each unit.

$$
\begin{array}{ll}
\text { If } P_{g i}>P_{g i}^{\max }, & \text { set } P_{g i}=P_{g i}^{\max } \\
\text { If } P_{g i}<P_{g i}^{\min }, & \text { set } P_{g i}=P_{g i}^{\max }
\end{array}
$$

Step 5 :Calculate total generated power.

Step 6 :Calculate mismatch in power which is given by following equation.

$$
\Delta P=\sum_{i=1}^{N g} P_{g i} P_{d}
$$

Step 7 :If $\Delta \mathrm{P}<\varepsilon$, then stop calculation and calculate the generation cost. Otherwise go next step.

$$
\begin{gathered}
\text { If } \Delta P>0 \text {, then } \lambda=\lambda-\Delta \lambda . \\
\text { If } \Delta P<0 \text {, then } \lambda=\lambda+\Delta \lambda .
\end{gathered}
$$

Step 8 :Repeat the procedure from step 3.

\subsection{Artificial Bee Colony Algorithm}

$\mathrm{ABC}$ algorithm is a new recent intelligent optimization algorithm based on swarm practices, defined algorithm by Dervis Karaboga in 2005. It has been developed by simulating the intelligent behavior of honey bees. In $\mathrm{ABC}$, artificial bees fly around multidimensional search space and the employed bees choose their food source depending on the experience of themselves. The onlooker bees choose food sources based on their nest mates experience and adjust their positions. Scout bees fly and choose the food sources randomly without using experience. The 3 main components of the process are:-

Food Sources: In order to select a food source, a forager bee evaluates several properties related to the food source such as its closeness to the hive, richness of the energy, taste of its nectar, and the ease or difficulty of extracting this energy.
For the simplicity, the quality of a food source can be represented by only one quantity although it depends on various parameters mentioned above.

Unemployed foragers: A forager bee that looks for a food source to exploit is called unemployed. It can be either a scout who searches the environment randomly or an onlooker who tries to find a food source based on the information provided by the employed bee.

Unemployed foragers: A forager bee that looks for a food source to exploit is called unemployed. It can be either a scout who searches the environment randomly or an onlooker who tries to find a food source based on the information provided by the employed bee.

Main steps of ABC algorithm for ELD problems are as follows:

Step 1: Initialize the population of solutions with in boundaries of the system

$$
P=P^{\min }+\operatorname{rand} *\left(P^{\max }-P^{\min }\right)
$$

Step 2: Calculate the objective function and fitness of each solution. Store the best fitness as Pbest solution.

Step 3: A mutant solution is formed using a randomly selected neighbour,

$$
P_{\text {kmutant }}=P_{k}(i)+\left[\left(P_{j}(i)-P_{k}(i)\right) *(2 * \text { rand }-1)\right]
$$

where $\mathrm{j}$ is the randomly selected neighbour and $\mathrm{i}$ is a random parameter

Step 4 :Replace $\mathrm{P}_{\mathrm{kmutant}}$ by $\mathrm{P}_{\mathrm{k}}$, if the mutant has higher fitness or lower fuel cost of generation.

Step 5: Repeat the above procedure for all the solutions

Step 6: Probability of each solution is calculated as

$$
\text { Probability }(i)=\text { fitness }(i) / \sum_{i=1}^{N_{P} / 2} \text { (fitness) }
$$

Where $N_{P}$ is total number of bees in the hive. In the hive, half of the population is of employed bees and another half is of onlooker bees.

Step 7: The solution $\mathrm{P}$ is selected if its probability is greater than a random number,

If (rand < probability (i))

Solution is accepted for mutation

Else

Go for next solution

Counter is incremented

While $($ Counter $=$ population $/ 2)$

Step 8: Again the best $P$ is determined. Replace $P$ by random $\mathrm{P}$ if its trial counter exceeds threshold.

Step 9: Repeat the above for maximum number of iterations. Step 10: The Pbest and F (Pbest) are the best solution and near global minimum of the objective function.

\section{Results and Discussions}

The Lambda iteration and artificial bee colony methods are implemented for three generating units. The results of both the methods are compared. All the programming has been done in MATLAB environment. 


\section{International Journal of Science and Research (IJSR) \\ ISSN (Online): 2319-7064}

Index Copernicus Value (2013): 6.14 | Impact Factor (2015): 6.391

Table 1: Generating units and cost coefficient for 3 unit system

\begin{tabular}{|c|c|c|c|c|c|}
\hline $\begin{array}{c}\text { Unit } \\
\text { Number }\end{array}$ & $\begin{array}{c}\text { Power } \\
\text { Minimum }\end{array}$ & $\begin{array}{c}\text { Power } \\
\text { Maximum }\end{array}$ & $\mathbf{a}_{\mathbf{i}}$ & $\mathbf{b}_{\mathbf{i}}$ & $\mathbf{c}_{\mathbf{i}}$ \\
\hline 1 & 35 & 210 & 0.03546 & 38.30553 & 1243.53110 \\
\hline 2 & 130 & 325 & 0.02111 & 36.32782 & 1658.56960 \\
\hline 3 & 125 & 315 & 0.01799 & 38.27041 & 1356.65920 \\
\hline
\end{tabular}

Table: 1 shows the input data for three generating units. Power minimum is lower bound of generator whereas power maximum means upper bound of generator and cost coefficients of each units are shown by $a_{i}, b_{i}$ and $c_{i}$.

The loss coefficient matrix is given by:

The loss coefficient matrix is given by:

$$
B=\left[\begin{array}{lll}
0.000070 & 0.000025 & 0.000030 \\
0.000030 & 0.000069 & 0.000032 \\
0.000025 & 0.000032 & 0.000080
\end{array}\right]
$$

Table 2: Comparison of test results for Three Generating units

\begin{tabular}{|c|c|c|c|}
\hline $\begin{array}{c}\text { Power } \\
\text { Demand (MW) }\end{array}$ & Performance & $\begin{array}{c}\text { Traditional } \\
\text { Method }\end{array}$ & $\begin{array}{c}\text { Artificial Bee } \\
\text { Colony }\end{array}$ \\
\hline \multirow{2}{*}{400} & Power Loss(PL) & 7.62391 & 7.5496 \\
\cline { 2 - 4 } & Total Fuel Cost Rs/hr & 20903.7 & 20828.5767 \\
\hline \multirow{2}{*}{500} & Power Loss(PL) & 12.1619 & 11.8573 \\
\cline { 2 - 4 } & Total Fuel Cost Rs/hr & 25733.7 & 25495.9523 \\
\hline \multirow{2}{*}{700} & Power Loss(PL) & 23.9839 & 22.487 \\
\cline { 2 - 4 } & Total Fuel Cost Rs/hr & 35614.4 & 35438.019 \\
\hline
\end{tabular}

Table: 2 shows the summarized result of ELD problem for load demand of 400MW, 500MW and 700MW by the ABC algorithm and lambda iteration method. Form Table: 1 it is clear that $\mathrm{ABC}$ algorithm gives optimum result in terms of minimum fuel cost and the losses are also reduced to some extent. For load demand 400MW, $500 \mathrm{MW}$ and 700MW, total fuel cost obtained by ABC are $20828.5767 \mathrm{Rs} / \mathrm{hr}, 25495$ $\mathrm{Rs} / \mathrm{hr}$ and $35438.019 \mathrm{Rs} / \mathrm{hr}$ respectively where as by lambda iteration method they are $20903.7 \mathrm{Rs} / \mathrm{hr}, 25733.7 \mathrm{Rs} / \mathrm{hr}$ and 35614.4 Rs/hr respectively. So from the above results we can conclude that $\mathrm{ABC}$ gives better results than LIM.

\section{References}

[1] Adil Baykasoglu, Lale Ozbakır, Pınar Tapkan, "Artificial Bee Colony Algorithm and Its Application to Generalized Assignment Problem", University of Gaziantep, Department of Industrial Engineering, Turkey.

[2] M. Basu and G. K. Mahanti, "Firefly and artificial bees colony algorithm for synthesis of scanned and broadside linear array antenna", Progress in Electromagnetic Research B., 32, pp.169-190 (2011).

[3] Ashish Dhamanda, Arunesh Dutt, Surya Prakash and A.K. Bhardwaj, "A traditional approach to solve economic load dispatch problem of thermal generating unit using MATLAB programming," IJERT vol.2 Issue 9, September 2013, 3147-3152.

[4] Serhat Duman, Aysen Basa arsoy, Nuran yorukeren, “ Solution of Economic Dispatch Problem using
Gravitational Search Algorithm”, Electrical Power and Energy Systems,pp. 54-59.

[5] Arunesh Dutt, Ashish Dhamanda, "Classical approach to solve economic load dispatch problem of thermal generating unit using MATLAB programming," IJERT vol.2, Issue 10, October 2013, 1384-1389.

[6] S. Hemamalini and Sishaj P Simon, "Economic/ Emission load Dispatch using Artificial Bee Colony Algorithm", ॥ Int. Conf. on Control Communication and Power Emgineering-2010, pp.338-343.

[7] Swarnkar K.K., AS.P, "Economic load Dispatch Problem with Reduce Power losses using Firefly Algorithm", Journal of Advanced computer science and technology, vol. 1, pp. 42-56, 2012.

[8] Santanu Kumar Nayak, Krishnanand K.R. , B.K. Panigrahi , P.K.Rout , "Application of Artificial Bee Colony to Economic Load Dispatch Problem with Ramp Rate Limits and Prohibited Operating Zones ", Silicon Institute of Technology, Bhubaneswar, Orissa, India,pp. 1237-1242.

[9] P V Rama Krishna, R Krishna, "Bees Colony Optimization Technique to Solve Optimal Dispatch of Generating Units", E.E.E, Gitam University.

[10] Ganga Reddy Tankasala , "Artificial Bee Colony Optimisation for Economc Load Dispatch of a Modern Power system " ,International Journal of Scientific \& Engineering Research, Volume 3, Issue 1, January-2012 , pp. 1-6.

[11]Dervis Karaboga, Bahriye Akay, "A comparative study of Artificial Bee Colony algorithm”, Erciyes University, The Department of Computer Engineering, Melikgazi, 38039 Kayseri, Turkey, pp 108-132.

[12]R. Murugan, M. R. Mohan, "Modified Artificial Bee Colony Algorithm For Solving Economic Dispatch" , ARPN Journal of Engineering and Applied Sciences , VOL. 7, NO. 10, OCTOBER 2012, pp. 1353-1366.

[13] Gaurav Prasad Dixit , Hari Mohan Dubey, Manjaree Pandit, B. K. Panigrahi, "Artificial Bee Colony Optimization for Combined Economic Load and Emission Dispatch ", Chennai and Dr.MGR University Second International Conference on Sustainable Energy and Intelligent System (SEISCON 2011), July. 20-22, 2011, pp-340-345.

[14] Ganga Reddy Tankasala , "Artificial Bee Colony Optimisation for Economc Load Dispatch of a Modern Power system " ,International Journal of Scientific \& Engineering Research, Volume 3, Issue 1, January-2012 , pp. 1-6.

[15] S. Vairamuthu, "Analysis and Comparison of Conventional Methods and Artificial Intelligence Techniques to Solve the Economic Load Dispatch Problem", International Journal of Innovative Research in Science, Engineering and Technology, pp. 1520-1527. 